\title{
Finger-in-glove sign in congenital bronchial atresia
}

\author{
Miguel Ariza-Prota MD¹, José Luis Diez Jarilla MD, Amador Prieto MD², \\ Ana Pando-Sandoval MD ${ }^{1}$, Pere Casan MD ${ }^{1}$
}

A 60-year-old woman was referred to the authors' hospital in 2012, with a three-month history of nonproductive cough. She had no chest pain, night sweats or fever. She had no known toxic habits, nor surgical or medical background of interest. The chest $\mathrm{x}$-ray showed loss of normal lung markings in the left upper lobe and a rounded, branching opacity mass lesion in the area of the left hilum (finger-in-glove

sign) (Figure 1A). A computed tomography scan of the chest showed mucoid impactation, segmental hyperlucency and decreased vascularity of the left upper lobe (Figure 1B). Three-dimensional reconstruction of the bronchial tree revealed an atretic apicoposterior segmental bronchus of the left upper lobe confirming the diagnosis of congenital bronchial atresia (Figure 1C).

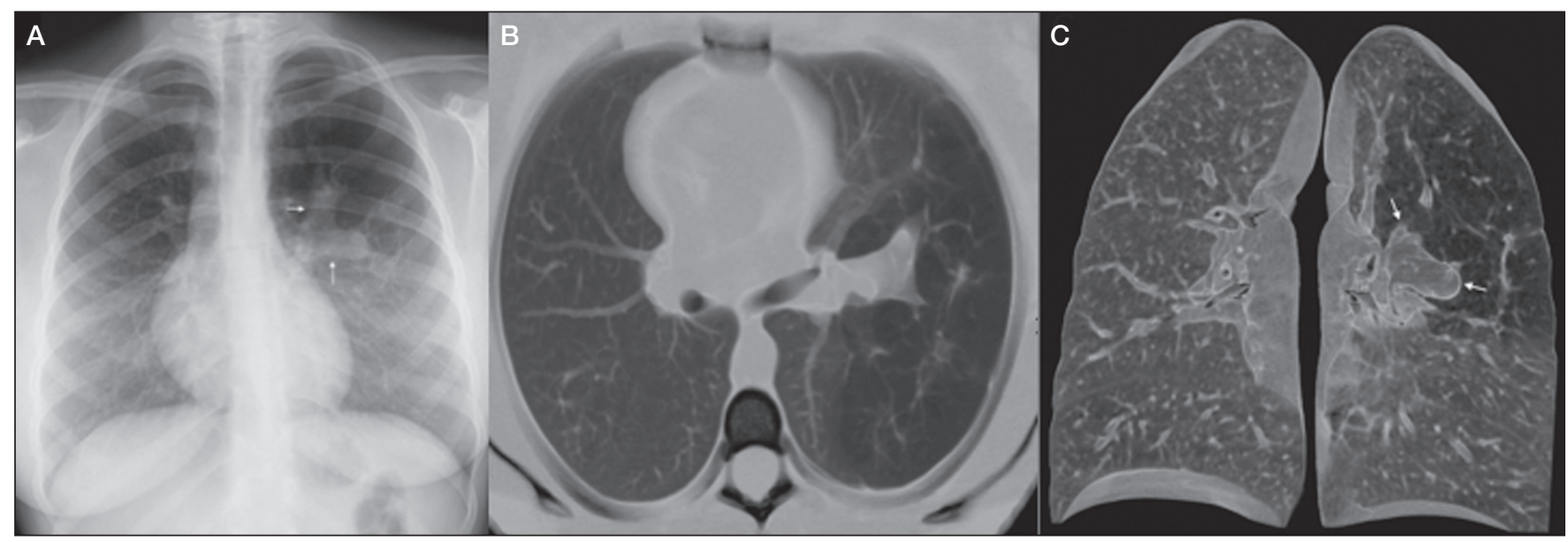

Figure 1) A Posteroanterior radiograph showing loss of normal lung markings in the left upper lobe and a rounded, branching opacity mass lesion (glove-infinger sign) in the area of the left hilum (white arrow). B Axial computed tomography image revealing mucoid impaction, segmental hyperlucency and decreased vascularity in the left upper lobe. C Three-dimensional reconstruction of the bronchial tree. No division of the corresponding bronchi, confirming the diagnosis of left upper lobe congenital bronchial atresia (arrows)

\section{KEY LEARNING POINTS}

- Congenital bronchial atresia is a rare anomaly characterized by normal bronchial ramification from a central blind bronchial sac filled with mucus (mucocoele). The regional hyperinflation is due to a check valve mechanism in the collateral ventilation through the alveolar pores of Kohn, the bronchoalveolar channels of Lambert, or the interbronchiolar channels.

- Distal to the bronchial atresia secretions accumulate, leading to mucoid impaction surrounded by segmental hyperlucency caused by a combination of trapped air and oligaemia.

- The apicoposterior segmental bronchus of the left upper lobe is most commonly affected.

- Sixty percent of patients are asymptomatic, their anomaly being discovered on a routine chest radiograph.

- Computed tomography (with contrast if necessary) is the diagnostic test of choice.

- The differential diagnosis of finger-in-glove sign includes mucus impaction due to cystic fibrosis, allergic bronchopulmonary asperigillosis, broncholithiasis, foreign body aspiration and malignancies.

\section{REFERENCES}

1. Nussbaumer-Ochsner Y, Kohler M. Finger-in-glove sign in bronchial atresia. Thorax 2011;66:182.

2. Jederlinic PJ, Sicilian LS, Baigelman W, Gaensler EA. Congenital bronchial atresia. A report of 4 cases and a review of the literature. Medicine 1986;65:73-83.

3. Martinez S, Heyneman L, McAdams H, et al. Mucoid impactions: Finger-in-glove sign and other CT and radiographic features. Radiographics 2008;28:1369-82.

${ }^{1}$ Hospital Universitario Central de Asturias (HUCA). Instituto Nacional de Silicosis (INS). Área del Pulmón. Facultad de Medicina. Universidad de Oviedo. Oviedo. España; ${ }^{2}$ Hospital Universitario Central de Asturias (HUCA). Departamento de Radiología. Oviedo, España. Correspondence: Dr Miguel Angel Ariza Prota, Instituto Nacional de Silicosis (INS), Área del Pulmón, Hospital Universitario Central de Asturias (HUCA), Facultad de Medicina, Universidad de Oviedo, Avenida Roma s/n, Oviedo, Asturias 33011, Spain.

Telephone 34-69006806, e-mail arizamiguel@hotmail.com 


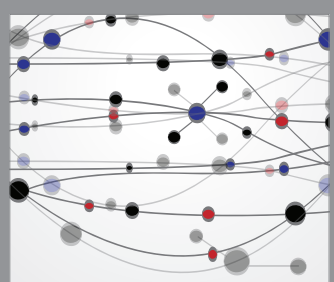

The Scientific World Journal
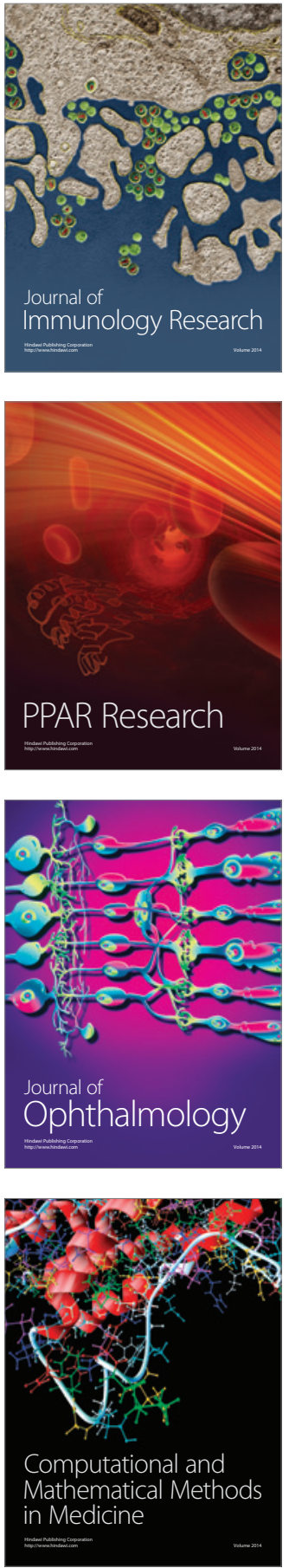

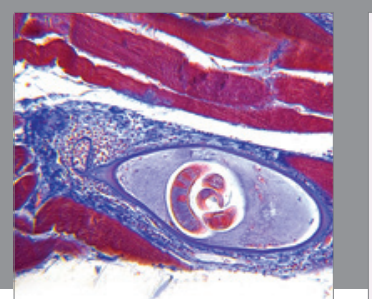

Gastroenterology Research and Practice

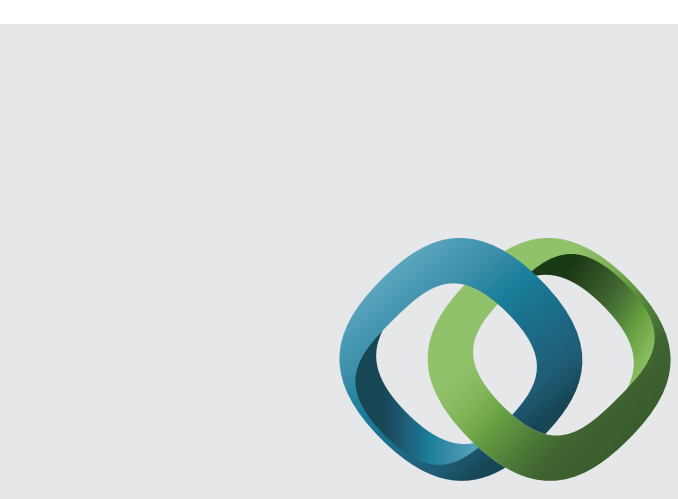

\section{Hindawi}

Submit your manuscripts at

http://www.hindawi.com
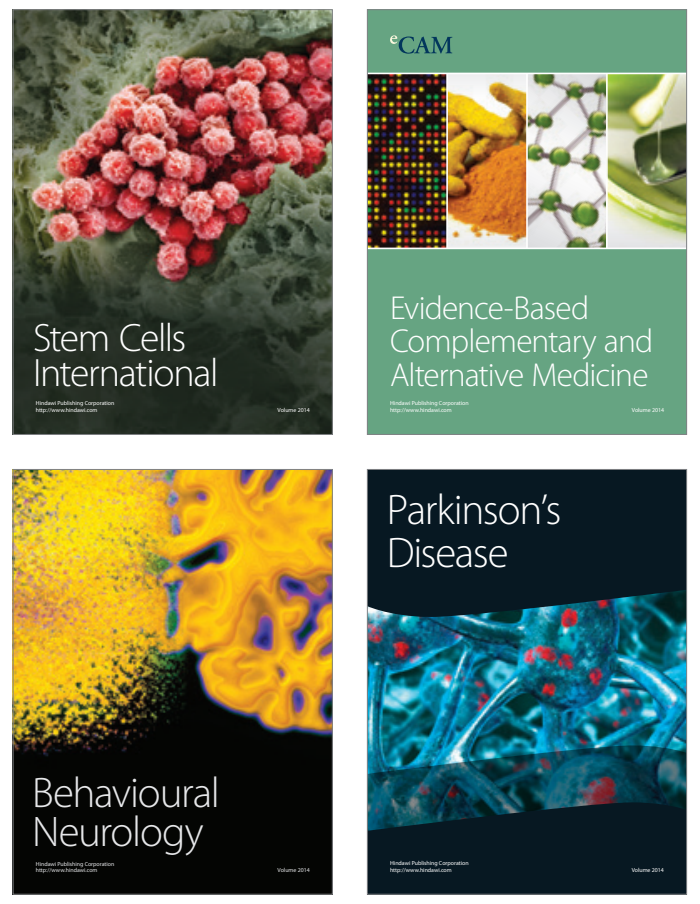
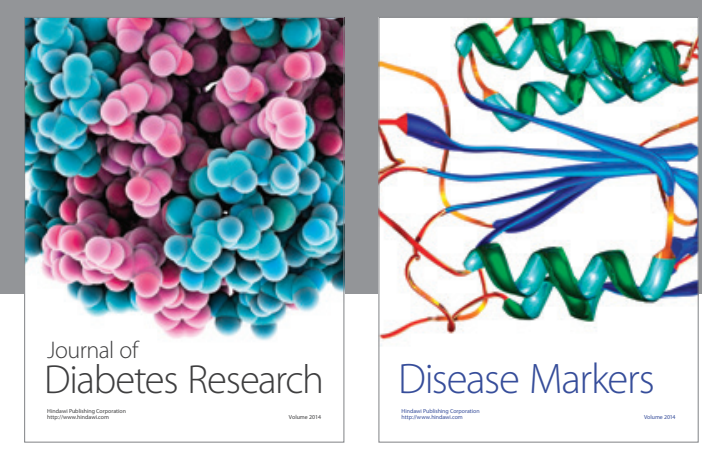

Disease Markers
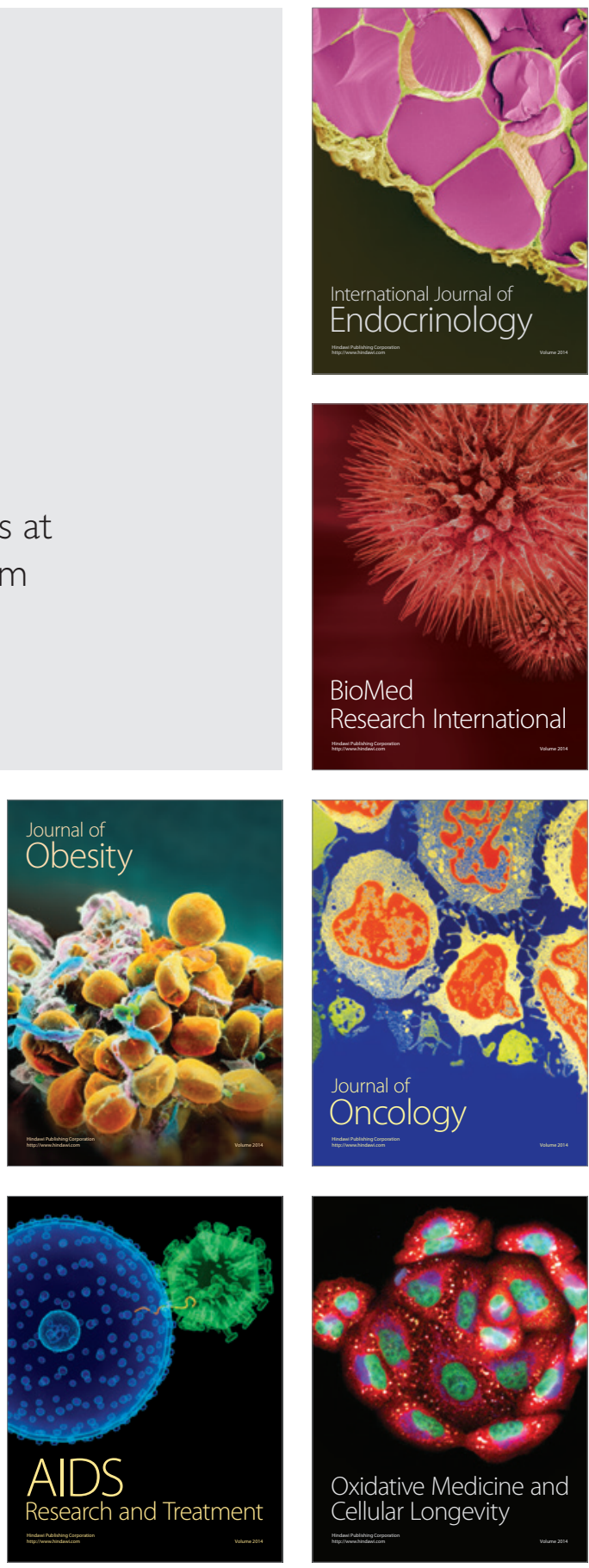